inch from the end. The back end of the tube is closed by a glass window and there is a tap to which an indiarubber bellows can be attached so that the bowel can be inflated. This instrument is in many ways a grest improvement upon its predecessors. Some of the earliest electric sigmoidoscopes were not sterilisable, as the electric light and connexions were an integral part of the tabe. In this instrument the lamp can be removed and the tube sterilised in the ordinary way. One of the great features of this sigmoidoscope is the method of passing it; practically speaking, after the tube has passed the first six inches the tip does not touch the rectal wall; it is therefore impossible for the tube to cause any damage to the wall of the bowel, however diseased the latter may be. The tube is passed as follows. The patient is placed in the knee-elbow position or in the semi-prone position with the buttocks raised on a cushion. The lamp portion of the tube is removed and the obturator inserted. The tube is then warmed by holding it for a moment in a stream of hot waterthis is better than dipping it into water as the interior of the tube is not wetted-and then thoronghly vaselined. The tube is passed gently into the rectum for about six inches; the obturator is then removed and the lamp and back glass are inserted. If on looking into the tube the mucous membrane is seen to be in contact with the end the rectum is inflated by a squeeze of the bellows so as to push away the mucous membrane. The tabe is then pushed into the hollow of the sacrum by tilting the point upwards; this enables the point of the tube to clear the anterior rectal valve. It must then be tilted downwards so as to clear the sacral prominence and enter the last loop of the sigmoid; it is also usually necessary to turn the point slightly to the right side. The tube should be passed by looking for the lumer of the gut and when this is seen giving a light puff with the bellows so as to open up the bowel, the tube being then pushed into the dilated portion. This procedure is repeated until the tube has been passed to its full length. A lot of air should not be pumped into the rectum, as this will cause the patient considerable discomfort, but the bowel should be inflated by light puffs with the bellows so as to push aside the walls of the bowel in front of the tube. Sometimes if the growth is on the anterior wall of the bowel it may be passed over during the passage of the tube without being seen, as one naturally follows the posterior wall while passing the tube. While withdrawing the tube, however, the whole lumen of the bowel comes into view and any growth is easily detected. When a growth is seen its position and size are easily ascertained and by pushing it gently with the end of the tube one can tell whether it is fixed or moveable.

It is possible with this instrument to obtain a view of the bowel as high as the top of the sigmoid flexure, though the distance to which one can pass the tube depends very much upon the mobility of the sigmoid flexure and upon its having a long mesentery. In one case in which there was an atonic condition of the bowel I was able to see well into the descending colon, but I believe that this is only possible in exceptional cases. By removing the window at the back of the tube and passing suitable instruments down it applications may be made to the growth or even pieces removed for microscopical examination. It is very important not to remove the window until the air pressure in the tube has been reduced, otherwise the sudden rush of air may prolapse the mucous membrane into the end of the tube and injure it. It needs a certain amount of practice before this instrument can be used satisfactorily. In this respect it resembles the cystoscope, laryngoscope, ophthalmoscope, \&c., all of which need practice not only in using them but in interpreting what is seen before their real value can be appreciated. The passage of the sigmoidoscope is not in the least painful and but slightly uncomfortable ; it is not necessary to administer an anæsthetic. The follow. ing case demonstrates very well the value of this method of diagnosis.

The patient was a man, aged 71 years. When $I$ first saw him he complained of constant diarrhoea and the passage of blood and slime by the rectum. He stated that these symptoms had only developed during the last two or three months and that he had previously been in good health. From his symptoms it seemed almost certain that he was suffering from a carcinoma of the rectum. On examining the rectum with the finger nothing could be felt and on examining with a six inch rectal tube nothing could be seen. Palpation of the abdomen and a bimanual examination also

gave negative results, although the abdominal walls were very lax. As I felt certain that there must be a growth somewhere either high up in the rectum or in the sigmoid flexure I examined him with the sigmoidoscope a week later at St. Mark's Hospital. I was then able to see the growth, which was of about the diameter of a two shilling piece it was situated on the anterior wall of the bowel at the lower end of the sigmoid flexure and on gently pressing it with the end of the tube $I$ was able to ascertain that it was moveable. About a week later, while the patient was making up his mind as to whether he should submit to an operation, symptoms of intestinal obstruction appeared and he was admitted into the West London Hospital where he was operated upon by Mr. O. R. B. Keetley who, knowing that I was interested in the case, kindly asked me to be present at the operation. On opening the abdomen the growth was found to be exactly as it had been diagnosed by means of the sigmoidoscope. It was found to be removeable but considering the patient's condition Mr. Keetley very wisely decided to perform a preliminary colotomy. The appearance of the growth as seen through the sigmoidoscope is shown in Fig. 2. Fig. 3 shows the appearance seen in another case of medullary carcinoma of the sigmoid flexure.

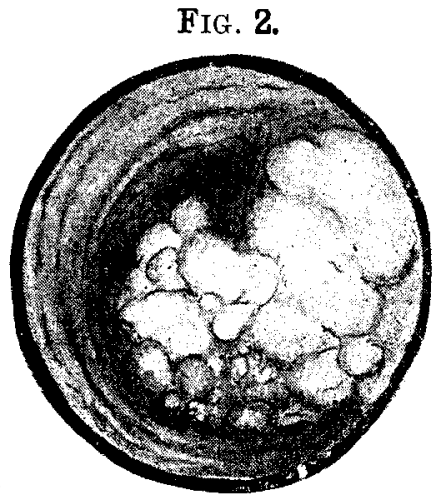

Appearance of the growth seen through the sigmoidoscope.
FIG. 3

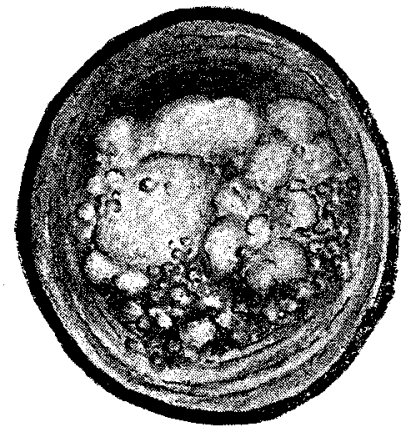

Medullary carcinoma of the igmoid flexure of a man aged 39 years, seen through the sigmoidoscope.

I believe if all patients were examined in this way who complain of symptoms which may be the result of a new growth in the rectum or sigmoid flexure-such as the recen onset of obstinate constipation withont obvious cause, the frequent passage of mucus or of blood and mucus, frequent colic only relieved by large doses of aperients, \&c.that many cases of malignant disease of the lower bowel would be detected at an early stage when complete removal is still possible, instead of the majority of such cases only being diagnosed when removal is very dangerous or altogether impossible as is the case at present.

Cavendish-place, $\mathrm{W}$

\section{STRANGULATION OF THE FULLY DE- SCENDED TESTICLE FROM TORSION OF A PEDUNCULATED MESORCHIUM.}

BY G. H. EDINGTON, M.D., F.F.P.S. GLASG., SURGEON TO THE OUT-PATIENT DEPARTMENTS OF THE WESTERV INFIRMARY AND OF THE ROYAL HOSPITAI FOR SICK CHILDREN, GLASGOW.

THE rarity of the above condition and the special features of this case are my excuse for publishing the following. I shall first briefly describe the case and shall then draw attention to some points in connexion with it.

The patient was a baby, aged seven months, who was brought to the out-door department of the Royal Hospital for Sick Children, Glasgow, on Sept. 10th, 1903, on account of swelling of the scrotum. The mother stated that the swelling had been observed on the previous day. No cause for the condition was known and it did not seem to trouble the patient in any way, On examination the left half of the scrotum was found to be much swollen, of the shape and size of a Tangerine orange, and very hard; the skin was bright red in colour, thickened and glazed, and hotter than the surrounding parts, and apparently acutely 
inflamed. The swelling and induration extended some way up on the cord but did not reach the external inguinal ring. Trxamination did not cause any pain. Hernia was excluded and it was thought that the condition was one of acute orchitis.

In view of the acuteness of the inflammation and the high degree of tension in the part it was thought proper to incise the swelling there and then and, chloroform having been administered, this was done. A vertical cut was made in the front of the swelling and exposed very cedematous subcutaneous tissue which bled freely. Successive cuts were made through the layers of the scrotum until the tunica vaginalis was opered. The testicle when exposed was found to be swollen, the body being of a purple colour and having engorged veins on its surface; behind was the much enlarged epididymis, resembling very dark blood clot. No escape of fluid was observed when the tunica was opened. The strangulated organ, with its tunica, was removed by peeling the lat ter oft from the inner surface of the scrotal sac. This was casly cune on acccunt of the odematous condition of the scrotal tissues. The cord was ligatured above the pointed upper end of the tunica. The cavity left was packed with iodoform gauze and the incision was sutured so as to leave the gauze protruding from its lower end. Uneventful healing occurred.

On examination of the specimen after removal it was found that the testicle was connected with the posterior part of the tunica vaginalis by a narrow pedicle, instead of, as is usual, by an attachment extending almost the complete length of the epididymis. The pedicle was at the upper pole of the organ and lay to the inner side of the gland. It had undergone a complete twist from within outwards (from right to left) so that the body of the testis lay in its proper situation, anterior to the epididymis. On untwisting the pedicle it was markedly white and bloodless, contrasting with the discoloured testicle; it was flattened from side to side and had a vertical measurement of four millimetres. The upper end of the tunica tapered and extended a short distance up on the front of the cord. The cord presented no apparent abnormality. The testicle measured as follows : vertically, 1.75 centimetres; transversely, 1.2 centimetres; antero-posteriorly (including epididymis), $2 \cdot 2$ centimetres; and the body of the testis alone, 1.4 centimetres. Dr. J. H. Teacher very kindly made a microscopical examination of the testicle. He reports that "the larger lobe is testicle, in a state of necrosis. The smaller lobule is epididymis. Between the two is a broad area of cedematous, bloodinfiltrated, and highly congested connective tissue which corresponds to the rete testis (hilum of the testicle) very much swollen. The epididymis is more closely incorporated with the testicle than is normal, owing to adhesion between the adjacent surfaces; the line of this adhesion is very plainly indicated by the remains of the two surfaces and a bed of leucocytes in and between them. The epididymis is less necrotic than the testis and its structure is plainly recognisable. The connective tissue is infiltrated with extravasated blood in large amount."

Etiology.-Strangulation of the testicle from torsion of the cord is rare and most of the cases recorded have occurred in testicles which were incompletely descended. The chief predisposing cause of torsion is abnormal mobility and this may come about from abnormal formation of the cord, or of the gubernaculum, or from excessively large and roomy tunica vaginalis. Scudder ${ }^{1}$ declares that "in all recorded cases of torsion of the cord operated upon, a deformity or a delay in development, or some abnormal condition about the testis, has been found. In all cases the testicle has been discovered to be freely moveable within the tunica vaginalis." Descent was incomplete "in 47 per cent." and " in every case there was a long mesorchium." He quotes Bramann to the effect that "more or less incomplete fixation of the testicle is seen in almost all anomalies of its development and in all disturbances of its descent." (If Bramann refers to incomplete fixation within the tunica I do not agree with the concluding phrase of the above sentence.) In the opinion of McAdam Eccles ${ }^{2}$ torsion is more common in the undescended organ and as predisposing causes there are, amongst others, "practical absence of a mesorchinm," and absence of the middle band of the gubernaculum. According to Jonathan Hutchinson,

1 Scudder: Annals of Surgery, vol. xxxiv., 1901, p. 234. 2 McAdam Eccles: The Imperfectly Descended Testis. London, jun., " "torsion of the cord occurs chiefly in those cases where the testis is abnormally mobile, either from imperfect descent or from absence of the usual adhesions to the bottom of the scrotum. These latter are, it is well known, largely the remains of the middle part of the gubernaculum, and vary much in their development in different individuals.' As will be seen from the illustration (Fig. 1), in the case

Frg. 1.
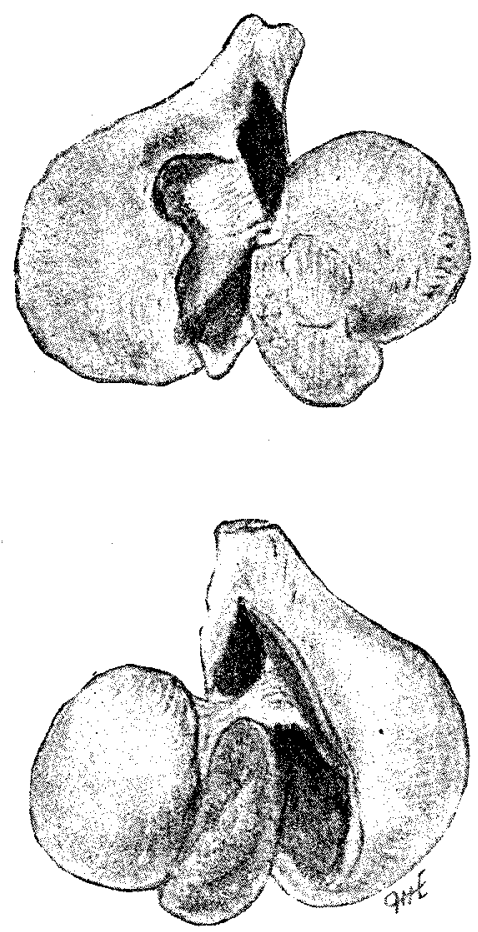

The upper figure represents the testicle and tunica vaginalis (from the mesial aspect) as on removal; the pedicle shows the torsion; the body of the testis is directed forwards and upwards. The lower figure shows the specimen from the lateral aspect, with the twist undone.

now reported the testicle hangs loose in the vaginal sac, the attachment being at the upper pole. This position of the gland corresponds with what Curling 4 has designated " reversion" of the testis, in which the upper pole of the gland is directed downwards along with the globus major, while the vas deferens springs from the tail of the epididymis, above the testicle. He continues: "This disposition of the organ does not affect the relations of the tunica vaginalis to the testicle and epididymis." 5 In my case, however, the relations are very much altered, the epididymis being wholly intratunical. The case reported by Lexer ${ }^{6}$ bears a superficial resemblance to this but on detailed examination it presents a quite different arrangement. The patient, aged 60 years, had noted an enlargement of the left scrotum three years previously, which came on quickly in two weeks' time. It was subject to repeated sudden increase in size during exertion but always returned again to its former dimensions. Two weeks before Lexer saw him there had been a sudden increase, accompanied by severe pain passing along the cord into the abdomen. The swelling was oval and smooth and of the size of a child's head; the scrotum over it was slightly reddened and cedematous; the testicle was not palpable but the cord was. Tapping withdrew bloody serum. Incision showed a bluish-black, glistening, gut-like structure free in the tunica, to which it was attached by a twisted stalk of the thickness of the little finger ; the twist was from without inwards. The necrosed testicle was removed with the parietal tunica. The mass proved on dissection to be testis plus a blood cyst; the epididymis lay behind and outside of the tunica. The pedicle contajned the abnormally lengthened vasa efferentia passing from the testis to the epididymis. Lexer advances the theory that the epididymis and vas deferens had descended first, owing to looseness or lengthening of the vasa efferentia. The testicle had descended later and had projected com pletely into the tunica. This, then, is not an example of "reversion."

3 Jonathan Hutchinson, jun.: Atlas of Pathology, New Sydenham Snciety, 1895, Fase. X.

4 Curling: Diseases of the Testis, p. 60. Fourth edition. London,
1878. 1878.

Loc. cit., p. 61

6 Lexer: Archiv für Klinische Chirurgie, 1894, Band 48, S. 201. 
In connexion with the suspension of the testicle in the peritoneal pouch by a pedicle, I may menticn the following case which occurred recently in the clinic of Sir Hector Cameron in the Western Infirmary and which I had the opportunity of dissecting. The patient was aged 15 years and the left testicle lay in the inguinal canal. Castration was performed in the course of operating for the radical cure of hernia on this side. The processus was widely open and the testicle, which was about half the size of its fellow (which was in the scrotum) was freely moveable, being attached to the wall of the processus by a stalk 3.5 centimetres long and 1.5 centimetres broad (Fig. 2, A). There was

FIG. 2.

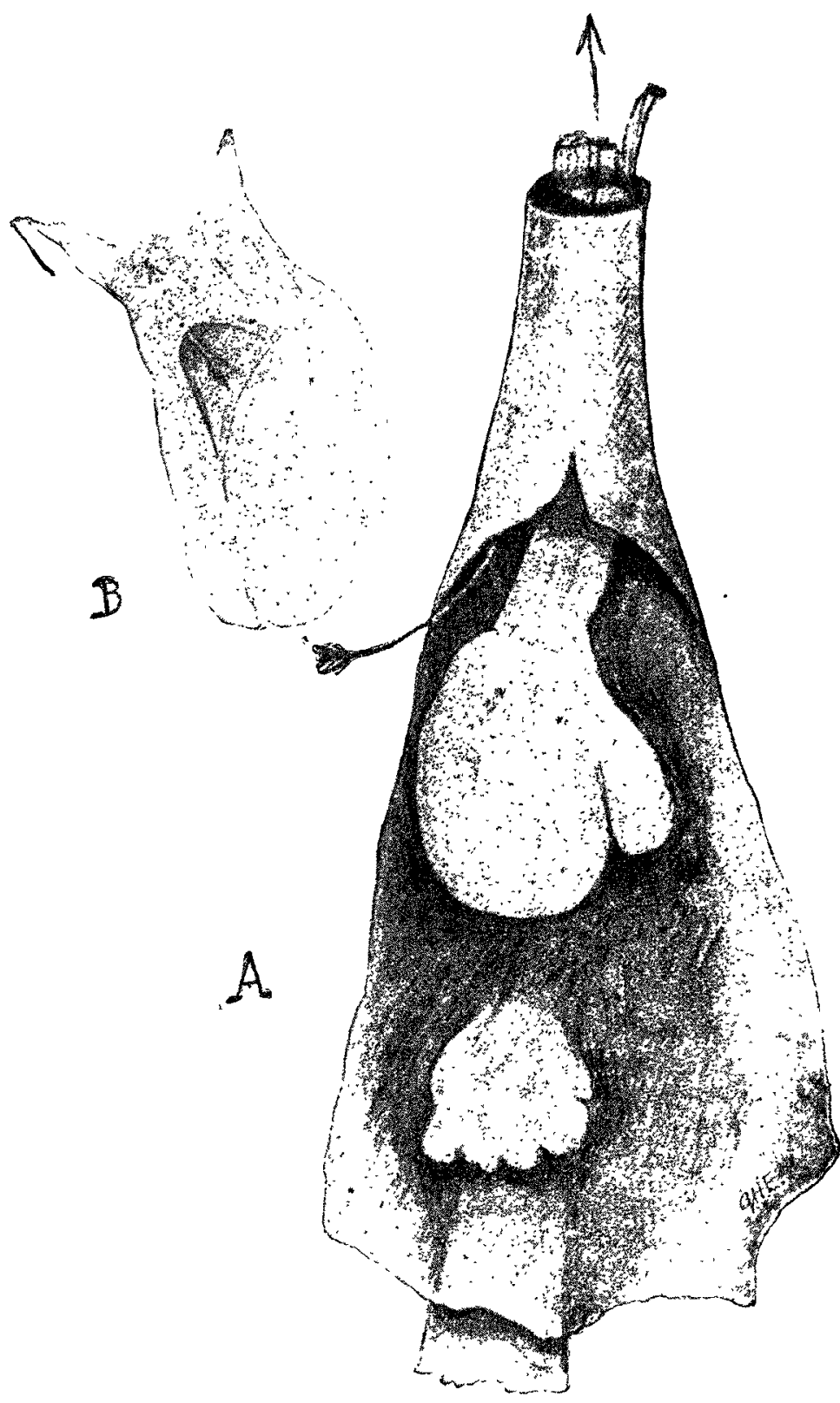

A, Testicle hanging in processus vaginalis. At the upper end are seen the elements of the cord behind the peritoneum of the processus, which is open, as indicated by an arrow. Below the testicle is the elevation of the serons membrane by the globus minor. and below this the gubernaculum. $B$, Digital pouch on the inner aspect of the testicle. The arrow shows the direction of the cavity. The testicle measured 3 centimetres vertically and 25 centimetres antero-posteriorly, including the epididymis. The pedicle. which was 35 centimetres in length, had a diameter of 15 centimetres. (Sir Hector Cameron's case. Compare with Fig. 3.)

a small epididymis on the posterior edge of the organ and the digital pouch was well marked on the inner aspect, being directed upwards for a distance of 1.5 centimetres (Fig. 2, B) The peritoneal wall was quite smooth behind the testis and its pedicle but lower down it was thrown into an irregular elevation from which the gubernaculum passed downwards towards the scrotum. On dissection the epididymis was found continued up in the pedicle to the wall of the processus where it turned down and ended in the globus minor at the elevation in the wall corresponding to the attachment of the gubernaculum. From this point it turned sharply up and was traced to the cord in the upper part of the specimen (Fig. 3).
In reading the literature of cases of torsion of the cord one is struck with the absence of detailed descriptions of the arrangement of the cord whether in a pedicle or otherwise. This want in the reports gives often a very indefinite impression of the conditions existing in the individual cases

FIG. 3.

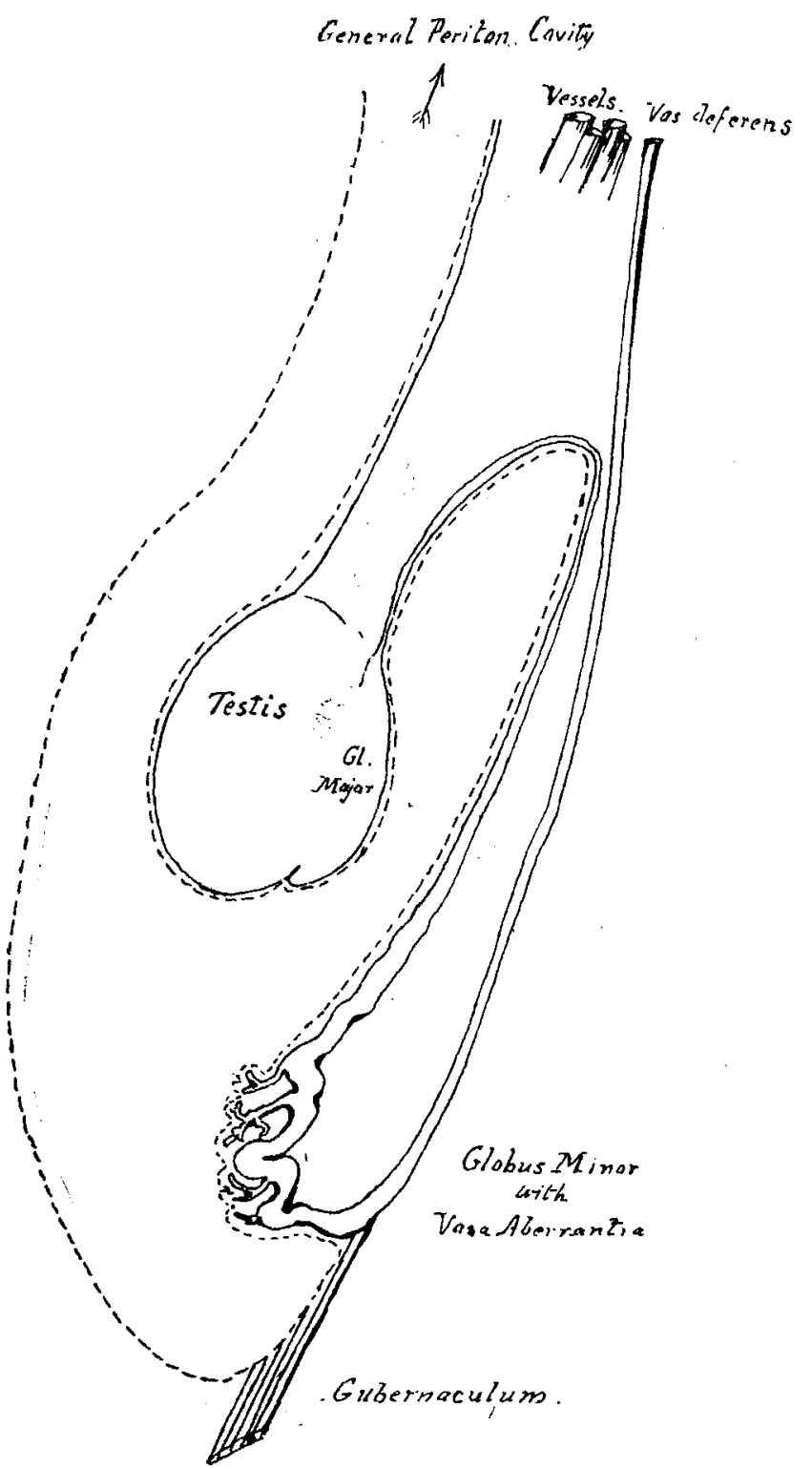

Scheme of epididymis, \&c., in pedunculated te sticle from the inguinal canal. The peritoneum is represented by the dotted line. (Sir Hector Cameron's case.)

Another source of confusion, however, is the different use of the term "mesorchium" by different observers. For example, Scudder ${ }^{7}$ does not describe, but figures his case as if possessed of an intratunical pedicle. Whipple's case $^{8}$ was reported on by Mr. J. H. Targett as one in which there was twisting of the epididymis "or mesorchium." Bryant $^{\prime}$ speaks of a "long mesorchium," and Hulke" uses the same expression. Page ${ }^{11}$ simply mentions that the twist occurred at the external ring and was undone by the motion for taking out a screw nail; no mention is made of the relations of the cord to the processus vaginalis. Johnson ${ }^{12}$ describes "gangrenous series of twists of the cord" but makes no mention of peritoneum. Nash ${ }^{13}$ treated his case by untwisting by external manipulation. Bardella ${ }^{14}$ describes a case of a fully descended testicle undergoing necrosis from torsion following tranma ; there was "complete absence of the mesorchinm." Contrasting with these there is Langton's ${ }^{15}$ very clear

\section{Loc. cit.}

8 Whipple and Targett: THE LANCET, May 16th, 1891, p. 1096 9 Bryant: TeE LANCET. Feb. 27th, 1892, p. 472.

10 Transactions of the Royal Medical and Chirurgical Society vol. xlix., 1866, p. 193. THE LANCET, July 30th, 1892, p. 257

11 Page : The LANCET, July 30th, 1892, p. 257.
12 Johnson : Annals of Surgery, vol, xvii., 1893. p. 282

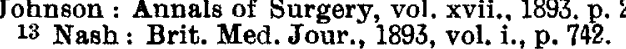

14 Bardella : Gazetta degli Ospedali e delle Cliniche. 1900 , reported 14 Bardella: Gazetta degli Ospedali o delle Cliniche, 1900, reported
in Jahresbericht für Ohirurgie, VI. Jahrgang, 1900, S. 901 . in Jahresbericht für Chirurgie, VI. Jahrgang, 1900, S. 901. p. 188 . 
description: "The viscus was very freely moveable in the sac of the tunica vaginalis, owing to an unusually extensive reflexion of the visceral layer of the serous covering." The testis was simply suspended in the sac "by the commencement of the cord." Then again, Taylor ${ }^{10}$ describes a case occurring four hours after birth. The testis when removed was round, smooth, and very tense, the insertion of the cord appearing like that of the "stalk of an apple."

In view of the above confusion I would suggest that excluding the conditions found in intra-uterine life previously to the descent of the organs the relation of the descended testicle to its serous covering be expressed in nomenclature analogous to that used in speaking of the intestine, Briefly, the testicle is normally fixed at the posterior part of the vaginal tunic by the reflexion of the visceral serosa from the sides of the epididymis to form the parietal layer. This arrangement corresponds to the relation of the peritoneum to the ascending colon, where there exists normally no mesocolon. Following this nomenclature we would describe the testicle as having normally no mesorchinm. Should, however, the gland not only project into, but hang loose in, the cavity of the tunica vaginalis, being attached to the posterior wall of the tunica by a membrane composed of two lajers of serosa and so resembling the mesentery of the small intestine, then we should be correct in terming such an attachment the "mesorchium." In my case the mesorchium, instead of extending almost the whole length of the epididymis, is represented by a small pedicle-like structure and the gland, therefore, is not ouly abnormally mobile but actually hangs free in the tunical sac. As contributing to abnormal mobility two other factors must be mentioned, both of them being present in this case. They are (1) absence of the middle band of the gubernaculum and (2) capacious tunical sac. The determining cause may be trauma or movements of the lower limbs or muscular effort. There was here no history of trauma and I think that we may assume that sudden contraction of the cremaster might, acting as it would on an abnormally mobile testicle, initiate the torsion.

Symptomatology.-This case is instructive as illustrating the absence of symptoms which would help to a correct diagnosis. As mentioned already, the case was looked on as one of acute orchitis. It would perhaps be more correct to speak of the superficial appearances as those of "periorchitis." I Fould draw attention to this point, as it has been mentioned by others as one of the conditions attending torsion of the spermatic cord. I would in this connexion also mention that there was apparently no collection of flaid in the tunical sac. This fact I observed carefully; the blood and serous exudation were wiped away after each successive cut in the scrotal tissue and when the tunica was opened there was no sudden escape of fluid. This absence of exudation in the tunical sac is all the more striking when one recollects its almost constant presence in inflammatory affections of the testicle.

The absence of constitutional disturbance calls for comment. In Scudder's paper ${ }^{17}$ such disturbance is mentioned as being usual; following on the severe sudden pain in the testicle there are nausea, vomiting, slight elevation of temperature, moderate degree of shock, and chill. It is all the more surprising that none of these should have been evident when every surgeon is familiar with the effect on the patient of handling the spermatic cord. Of course, they may have been present at the commencement of the torsion, but the mother distinctly averred that the child had never been ailing. In connexion with symptoms I would notice the age of the patient-seven months. This is very early so far as these cases go. The condition occurs most frequently in young adolescents, but in Taylor's case (vide supra) the patient was only four hours old.

Treatment.-So far as records show castration is the only treatment for this condition. Torsion is followed by sloughing or by atrophy in nearly all cases, even when the twist has been undone. If done early enough reposition of the displaced organ may have a happy result, as in Nash's case, ${ }^{18}$ where manipulation four and three-quarter hours after the onset was successful. Lexer's case also had had repeated attacks of torsion before the organ was finally removed. On the other hand, we have in veterinary practice the intentional production of sterility by torsion of the cord as a substitute

$$
16 \text { Tavlor: Brit. Med. Jour., 1897, vol. i., p. } 458 .
$$

is Loc. cit. for gelding. The efficacy of this practice has been borne out y experiment (Enderlen). ${ }^{19}$

In conclusion, the following points in this case are worthy of note: (1) extreme youth; (2) testicle fully descended; (3) no history of injury ; (4) absence of constitutional signs ; (5) local signs not diagnostic; and (6) presence of "reversion" with pedunculated mesorchium.

Glasgow.

\section{ON THE PROPHYLACTIC USE OF MOR- PHINE IN CASES OF SEVERE CEREBRAL INJURY.}

\section{BY J. A. MACDOUGALL, F.R.C.S. EDIN ,}

CONSULTING SURGEON TO THE OUMBERLAND INFIRMARY; SURGEON TO THE FRENCH PROTESTANT HOSPITAL AT CANNES.

THERE must be few men, leastwise Edinburgh men, whose student days lay in the early "sixties" who do not recall the suspicion which attached to the use of opium in cases of injuries of the head. Many of the best of surgeons would not venture to use it and the reason was not difficult to understand, for inasmuch as its proximate action was to produce a condition of torpor akin in its features to those which were the dreaded sequelæ of such traumatisms, it was natural to argue that its employment might predispose the sufferer to their advent. Mr. Spence, my revered master, who was for long as great an authority on head injuries north of the Tweed as his distinguished contemporary, Sir Prescott Hewett, on the south, was, on the whole, averse to its employment, and although when the acute symptoms of meningitis or arachnitis made their appearance and restlessness and delirium seized the patient he found throngh it a medium of soothing him I do not think that he ever regarded its use as a probably curative measure. And his teaching on this point, as on hosts of others pertaining to practical surgery, abode with me, and for many years, unless compelled by the appearance of grievous after-results, I eschewed the use of opinm in cerebral injuries, and although its employment when demanded carried with it comfort and quiet to the sufferer, that it played a highly important part in the treatment of the case was with me an uncertainty.

It was not until 1899, when an abstract of a valuable paper ${ }^{1}$ by Dr. J. Barr of Liverpool on Meningitis came under my notice, that I realised how freely morphine might be given in this disease, how excellent were the results attendant upon its employment, and how in all probability its beneficent action was brought about largely through its effects upon the vascular and nervous systems, inducing that condition of rest which, as Mr. Hilton so admirably taught, is nature's opportunity. Further and natural reasoning was this: if opium by its action on the nervous system quiets brain cells and lessens the functional activity of the nervous fibrils which connect them with one another, if it lesseus pain and removes the effects of peripheral stimuli, if it contracts cerebral arterioles and through the cardiac ganglia renders the heart's action slower and vascular pressure less pronounced, then its effects upon a brain that is traumatically damaged and that demands quiet for its repair can only be beneficial. And so I have found it, for if after severe brain injury the patient is kept gently under the influence of morphine convalescence has been more rapid and more steady, grave cerebral symptoms have been wanting, and the continuous rise in temperature which usually marks cerebral laceration and hæmorrhage has been notably absent. It may be argued, however, that in the antiseptic management of the wound lay the whole secret of success, but this is hardly so, for in common with others I have seen these characteristic and continuous rises in temperature where there was no external wound and where the element of sepsis was, so far as ordinary judgment could carry one, entirely absent. Be this as it may, a short record of the following cases will mayhap tend to strengthen my contention.

OASE 1 -Four years ago, in association with my friend Sir Henry Blanc, I was desired by Dr. Dicterlen to see with him a patient who the previous afternoon had attempted suicide by a pistol-shot wound of the head. We met

19 Enderlen: Deutsche Zeitschrift für Chirurgie, 1896, Band 43, Heft 1 and 2. Reported in Jahresbericht für Chirurgie (II. Jahrgang, 1896, S. 980)

1 Brit. Med. Jour., Nov. 18th, 1899 